\title{
ASSAYS TO DETERMINE THE PREDATORY ABILITY OF PERGAMASUS AGAINST CLOVER FLEA
}

\author{
T.M. EDEN, D.J. WILSON and D.L. HACKELL \\ AgResearch, Ruakura Research Centre, Private Bag 3123, Hamilton \\ Corresponding author: tina.eden@agresearch.co.nz
}

\begin{abstract}
Clover flea (Sminthurus viridis) is found throughout New Zealand and is a major economic pest of white clover (Trifolium repens) in localised areas of the North Island. Predatory mites are important biocontrol agents of clover flea in Australia, but little is known of the efficacy of the predatory mite species present in New Zealand. A major challenge to assessing mite efficacy has been poor survival of clover flea in laboratory assays. It was found that adult clover flea survival was higher when they were contained with soil, whereas soil was not essential for the survival of younger nymphs. The predatory ability of Pergamasus is still unclear, as there was significant mortality in one experiment containing the mites, but no significant difference in mortality in the assay that followed.

Keywords: clover flea, Sminthurus viridis, Pergamasus, biocontrol agent.
\end{abstract}

\section{INTRODUCTION}

Although clover flea (Sminthurus viridis L.) is present throughout New Zealand (Dumbleton 1938), severe damage to white clover (Trifolium repens) occurs in localised areas of the North Island only (Townsend et al. 1979; Wrenn et al. 1983). Pasture damage is caused by the nymphs and adults that can be present in high numbers from April through to December (Dumbleton 1938; Addison et al. 1992), with populations peaking in spring and autumn (Willoughby et al. 2002). In cases of heavy clover flea infestation, only the veins of the clover leaf and cuticle remain, giving the clover a white appearance (Dumbleton 1938). Clover flea damage reduces yield and deters stock which avoid eating pasture fouled by clover flea faeces (Pottinger 1983).

Insecticides and tolerant clover cultivars are currently used to manage clover flea populations in New Zealand. However, predatory mites are used successfully in Australia as biocontrol agents of clover flea. The predatory mites considered most important in Tasmania for the control of clover flea are the pasture snout mite, Bdellodes lapidaria, the spiny snout mite, Neomolgus capillatus, the European whirligig mite, Anystis baccarum, and the parasitid, Pergamasus longicornis (Ireson et al. 2001). In the high rainfall dairy pastures of Tasmania, it is thought that Pergamasus may replace B. lapidaria as the major predator of pasture Collembola (Ireson et al. 2001). While B. lapidaria and a Pergamasus species are found in New Zealand and have been observed to attack clover flea (D.J. Wilson, pers. comm.), their impact on clover flea populations is not clear.

This paper reports on assays to determine the predatory ability of Pergamasus on clover flea. The importance of containing the clover flea with soil was also evaluated.

\section{METHOD}

Pergamasus mites and clover flea were collected from AgResearch, Ruakura, using a modified Homelite HB $180 \mathrm{~V}$ blower/vac. The test apparatus used in the assays consisted of a $100 \mathrm{ml}$ specimen vial inverted over a $50 \mathrm{ml}$ vial, the two vials connected by taping the vial lids together. A clover leaf was placed in the upper vial with its petiole in tap water in the lower vial, having been threaded through a $3 \mathrm{~mm}$ hole pierced through 
both lids. A $30 \mathrm{~mm}$ diameter hole had been made in the upper vial for aeration and was covered with mesh voile.

In Experiment 1, three adult clover flea and two Pergamasus mites were contained in each specimen vial with a clover leaf. This was replicated 10 times. A further 10 vials were set up with clover flea only as controls. The vials were kept in a $18^{\circ} \mathrm{C}$ Controlled Environment Facility at 16:8 h light:dark for the duration of the experiment. The experiment was assessed at Day 7 whereby clover flea and Pergamasus survival was recorded. A clover flea feeding score was given for each clover leaf whereby $0=$ no feeding and $5=$ severe feeding damage.

For Experiment 2, the previous experiment was repeated except that approximately $5 \mathrm{~g}$ of untreated soil (Horotiu sandy loam) at $28 \%$ moisture content was placed in the upper vial lid. Two adults and one late-stage nymph were contained in each replicate instead of three clover flea adults as in Experiment 1. The experiment was assessed as above but on Day 6 instead.

Experiment 3 was a repeat of experiments 1 and 2 but clover flea nymphs were used instead of adults. The nymphs were younger than those used in Experiment 2. The experiment was assessed at Day 7 as in Experiment 1.

All data were analysed by a one-way analysis of variance (ANOVA) to separate the means. The data from Experiment 3 was analysed as four treatments due to the lack of mites in the treatment without soil.

\section{RESULTS}

Results from the three experiments are summarised in Table 1. Clover flea survival was very low in Experiment 1. However, the addition of soil in Experiment 2 improved clover flea survival to 97\% in the controls. Survival in Experiment 2 was significantly higher in the controls than in the mite treatment, as was feeding damage $(\mathrm{P}<0.05)$. Mite survival did not change with the addition of soil from Experiment 1 to Experiment 2.

TABLE 1: Percent survival of clover flea and Pergamasus mites, and clover flea feeding score, from Experiments 1 and 3 at Day 7 and Experiment 2 at Day 6.

\begin{tabular}{|c|c|c|c|c|c|c|}
\hline & \multicolumn{2}{|c|}{ Soil present } & \multicolumn{2}{|c|}{ Soil absent } & \multirow[b]{2}{*}{ SED } & \multirow[b]{2}{*}{$\mathrm{P}$-value } \\
\hline & Mites & Control & Mites & Control & & \\
\hline \multicolumn{7}{|l|}{ Expt 1 (adults) } \\
\hline$\%$ clover flea survival & $n d^{1}$ & nd & 17 & 4 & 6.5 & 0.055 \\
\hline Feeding score & nd & nd & 1.8 & 2.2 & 0.56 & 0.494 \\
\hline$\%$ Pergamasus survival & nd & & 70 & & & \\
\hline \multicolumn{7}{|l|}{ Expt 2 (adults+nymphs) } \\
\hline$\%$ clover flea survival & 57 & 97 & nd & nd & 12.1 & 0.004 \\
\hline Feeding score & 2.3 & 3.5 & nd & nd & 0.31 & 0.004 \\
\hline \% Pergamasus survival & 70 & & nd & & & \\
\hline \multicolumn{7}{|l|}{ Expt 3 (nymphs) } \\
\hline$\%$ clover flea survival & 73 & 88 & 80 & 67 & 12.7 & 0.457 \\
\hline Feeding score & 2.7 & 4.0 & 2.8 & 3.7 & 0.47 & 0.027 \\
\hline \% Pergamasus survival & 70 & & 5 & & & \\
\hline
\end{tabular}

${ }^{1}$ nd=not determined.

The presence of soil made no significant difference to clover flea nymph survival in Experiment 3. However, in the presence of soil, clover flea with mites fed significantly less $(\mathrm{P}<0.05)$ than the controls. The presence of mites had no significant effect on clover 
flea survival either with or without soil. In contrast to the first two experiments mite survival was significantly lower in vials without soil than in vials with soil.

\section{DISCUSSION}

Clover flea and the predatory Pergamasus mites have frequently been found together in pasture suction samples throughout the Waikato and Wairarapa regions. In Tasmania, Ireson et al. (2001) found Pergamasus to have a similar phenology as clover flea, with numbers of both species increasing to a seasonal maximum in late spring/early summer and mid-late autumn. Pergamasus play a role as predators of clover flea in Tasmania, as they have frequently been observed attacking this pest (Ireson et al. 2001).

Clover flea show a preference for the Leguminosae, particularly clover over other broad-leaved plants (Dumbleton 1938), with white clover (Trifolium repens) being the preferred host (Wrenn et al. 1983). Since white clover was provided as the food source, the poor survival of clover flea adults in Experiment 1 was unexpected. Adult survival was improved by adding soil in Experiment 2. Holdaway (1927) found that clover flea are soil eaters, and that adult females eat more soil during egg laying than at any other time. However, Holdaway (1927) also found that nymphs can survive for at least one generation without soil. This may explain the lack of difference in survival in Experiment 3 with and without soil when only nymphs were used.

Survival of the Pergamasus mites appeared not to be affected by the presence or absence of soil, with 70\% survival in Experiments 1 and 2 and the treatment with soil in Experiment 3. However, there was very high apparent mortality in Experiment 3 without soil. Very few mite cadavers were found in this treatment, which was unexpected, as mite cadavers had been seen in the previous experiments. It is possible that the mites may have been omitted in error or adult cannibalism had occurred. Cannibalism is rare amongst Pergamasus longicornus adults (Harris \& Usher 1978) and it is possible this is the same species used in the assay which is common in improved pastures in Europe and Australia (Ireson et al 2001). The high mite mortality made it difficult to compare the effectiveness of the mites on the nymphal stage of clover flea with and without soil.

Due to the low survival of clover flea in the control treatment of Experiment 1, the predatory ability of the mites could only be assessed from Experiments 2 and 3 . The mites had a significant effect on clover flea survival in Experiment 2 only. It is possible that adults are slower moving and easier prey than the nymphs. The mites may be more effective predators of the adults when soil is available. The mites were seen to hide amongst the soil, whereas the clover flea were either on the clover or the soil surface. Clover flea feeding was also significantly less when the mites were present but only when soil was included in both experiments 2 and 3 . This may also be due to the mites being more effective predators in the presence of soil, and so disrupting the feeding behaviour of the clover flea.

In conclusion, the age of the clover flea used in each experiment was found to affect the results. This indicates the importance of understanding the life stage and biology of the clover flea in order to develop good assays. The results from this work show that Pergamasus are a likely natural enemy of clover flea in New Zealand. Further work is required to determine the efficacy of this mite as a biocontrol agent of clover flea in New Zealand.

\section{ACKNOWLEDGEMENTS}

The authors thank the Northland Clover Pest Interest Group for funding this work and Bruce Willoughby for the initial concept. We also thank Dr Pip Gerard and Joanne Jensen for their valuable comments on early drafts of this manuscript.

\section{REFERENCES}

Addison PJ, Firth AC, Cliffe A, Popay AJ 1992. The effects of diflubenzuron on lucerne flea. Proceedings of the 45th New Zealand Plant Protection Conference: 197-200. 
Dumbleton LJ 1938. The lucerne flea (Sminthurus viridis) in New Zealand. The New Zealand Journal of Science and Technology 10: 197-211.

Harris JRW, Usher MB 1978. Laboratory studies of predation by the grassland mite Pergamasus longicornus Berlese and their possible implications for the dynamics of populations of Collembola. Scientific proceedings of the Royal Society of Dublin: A6 143-151.

Holdaway FG 1927. The bionomics of Smymthurus viridis Linn. or the South Australian Lucerne Flea. Council for Industrial and Scientific Research, Australian Pamphlet No. 4.

Ireson JE, Holloway RJ, Chatterton WS 2001. An overview of investigations into the use of predatory mites to control the lucerne flea, Sminthurus viridis (L.) (Collembola: Sminthuridae), in Tasmanian pastures. In: Proceedings of the 10th International Congress of Acarology. Halliday RB, Walter DE, Proctor HC, Norton RA, Colloff MJ ed. CSIRO Publishing, Collingwood, Australia. Pp. 444-452.

Pottinger RP 1983. Recent developments with pasture pests. Proceedings of the 35 th Ruakura Farmers' Conference: 99-105.

Townsend RJ, Pottinger RP, Rowe SJ, Hartley MJ 1979. Evaluation of alternative insecticides for lucerne flea on pasture. Proceedings of the 32nd New Zealand Weed and Pest Control Conference: 68-71.

Willoughby B, Cooper B, Panckhurst K, Wilson DJ 2002. Combining chlorpyrifos and diflubenzuron for effective management of clover flea (Sminthurus viridus). Proceedings of the 55th New Zealand Plant Protection Conference: 258-262.

Wrenn NR, Pottinger RP, Dentener PR, McGhie RA 1983. Evaluation of insecticides for lucerne flea control in pastures. Proceedings of the 36th New Zealand Weed and Pest Control Conference: 185-189. 